\title{
Interplay of Physical Activity and Vitamin D Receptor Gene Polymorphism on Bone Mineral Density
}

\author{
Ikumi Kitagawa ${ }^{1}$, Yasuo Kitagawa ${ }^{2}$, Teruo Nagaya ${ }^{3}$ and Shinkan Tokudome ${ }^{3}$
}

\begin{abstract}
The interplay of physical activity and vitamin D receptor (VDR) gene polymorphism in their effects on bone mineral density (BMD) was studied for 120 Japanese girls aged 18-19 years. BMD at distal radius in the group with the VDR genotype at the Apal site of $A a$ was significantly higher than that in the aa group, but this association disappeared in a group having the habit of physical activity. The Aa genotype gave a higher BMD than the aa genotype only in the group without the habit of physical activity. The habit of physical activity was associated with a higher BMD only in the aa genotype group. The similar interplay was observed in the VDR genotype at the Taql site. We thus suggest that physical activity and VDR genotypes affect BMD in independent mechanism to give a saturated level of BMD. Higher dietary calcium intake tended to be associated with higher BMD only in the Aa genotype, suggesting that the calcium intake and VDR genotype affect BMD in a synergistic mechanism.
\end{abstract}

J Epidemiol, $2001 ; 11: 22-232$

bone density. calcium intake, gene polymorphism, physical activity, vitamin $\mathrm{D}$ receptor gene

Many twin and family studies suggested that genetic factors account for as much as $80 \%$ of the variation in bone mineral density (BMD) ${ }^{1-3)}$. Among genetic factors, the vitamin $D$ receptor (VDR) gene has been considered to be important since its polymorphism accounted for up to $75 \%$ of the genetic effects ${ }^{4}$. This VDR theory has been under lively discus$\operatorname{sion}^{5,6)}$, and it is now under debate whether the VDR gene can regulate the sensitivity of BMD to environmental factors such as physical activity ${ }^{7}$ and calcium intake ${ }^{8,9)}$. A large cross-sectional study of 470 healthy premenopausal women aged 44-50 suggested that the inter-individual allelic variation in the VDR gene could modulate the influence of physical activity on BMD ${ }^{10}$. Nonetheless, the effect of the VDR genotype on bone density was of limited importance in the study population composed of physically active women aged 43 to 68 years ${ }^{11}$ ). Loading a progressive exercise three times a week for 18 months increased the BMD of a population aged $35-45$, but the effect was not associated with the VDR genotype ${ }^{12}$. Since these studies indicated a complex gene-environmental interac- tion, the age of the study population and the index of physical activity need to be carefully controlled in further studies.

By studying a population of Japanese girls with a narrow age window of 18-19 years, we showed recently that the polymorphism at ApaI site in VDR gene affects BMD in cooperation with an advanced age at menarche ${ }^{13}$. Our questionnaire about their history of physical activity during the age span of 13-18 years suggested that the habit of physical activity affects BMD in a distinct mechanism from that of the VDR genotypes.

\section{SUBJECTS AND METHODS}

One hundred twenty Japanese girls aged 18-19 years participated in the study. BMD was measured at the distal forearm of the non-dominant arm by dual energy $\mathrm{X}$-ray absorptiometry (DXA, DTX200, Osteometer, Denmark). Weight and height were also measured. The characteristics of this study population were summarized elsewhere ${ }^{13}$. Mean age, height; weight and BMI were $18.4 \pm 0.5,157.5 \pm 5.1 \mathrm{~cm}, 52.2 \pm 6.5 \mathrm{~kg}$ and

Received February 13, 2001; accepted June 19, 2001.

' Nagoya Seirei Junior Collage.

${ }^{2}$ Nagoya University Graduate School of Bioagricultural Sciences.

${ }^{3}$ Nagoya City University Medical School.

Address for correspondence : Ikumi Kitagawa, Ph.D. Nagoya Seirei Junior Collage 2 Seirei-cho, Seto, Aichi 489-0863, Japan. 
$21.0 \pm 2.3 \mathrm{~kg} / \mathrm{m}^{2}$ respectively. The Apal and $T a q I$ sites in the VDR gene were detected after amplification by the polymerase chain reaction ${ }^{13}$.

A self-administered questionnaire was used to determine the habitual physical activity and dietary calcium intake. As for the former, we asked about the participant's choice of either sports or cultural activities for the supplemental class during their junior (13-15 years old) and senior (16-18 years old) high school days. Observing the guidelines of the Ministry of Education, Culture, Sports, Science and Technology of Japan, all Japanese junior and senior high schools have such a supplemental class of at least one school hour per week which lets students enjoy either sports or cultural activities. Since we found that one third of our study population chose only cultural activities throughout the six years of their junior and senior high school period, we took advantage of this choice as an index of their habitual physical activity. Through an interview with such girls, we found that they tend to avoid any kind of sports. These girls were grouped into "No" habitual physical activity and the other girls, who had chosen sports at least for one semester, were grouped into "Yes". The mechanical strains worked on the skeleton during puberty and adolescence is the best index to know the mechanical effect on bone development but our present study revealed that habit of physical activity based on this questionnaire served as a reliable substitutive index of mechanical effect.

As for dietary calcium intake, we scored our participants' dietary habits by asking about the frequency with which they ate the following seven food groups; milk, milk products, bean and bean products, meat, fish, dried fish with bone, and green vegetables. In the Japanese dietary situation, these food groups account for about $65 \%$ of the calcium intake ${ }^{14}$. The frequency of taking one of these food groups was scored as follows: 4 points indicated taking everyday, 3 points meant $3-6$ times/week, 2 points meant $1-2$ times/week and 1 point meant never taking. The points were summed to calculate the total scores. An individual with a total score of more than 20 was grouped into "High", and one with a total score below 19 was grouped into "Low". No participants had the habit of taking calcium supplements or calcium-added foods.

The data were analyzed using the SPSS software package. Analysis of variance was used to examine the mean difference of BMD, the calcium intake and the habitual physical activity between VDR genotypes. The association of the BMD with physical activity and dietary calcium intake in each VDR genotype was examined by ANCOVA.

\section{RESULTS}

In this study, we analyzed the effects of habitual physical activity on BMD by indexing the choice of sports ("Yes") or cultural activities ("No") for the supplemental class during the participant's high school. Since BMD is a body size dependent measure, we first compared the height, the weight-and the lean body mass between "Yes" and "No" subgroups to find no significant difference (Table 1). Same was the case for "High" and "Low" subgroups of dietary calcium intake scored through the habit of eating calcium-containing foods (Table 1). These demonstrated that the habitual physical activity and dietary calcium intake on BMD (described below) were not influenced indirectly by difference of body size.

When the VDR genotype was not considered, habitual physical activity showed only a trend of association of higher BMD at distal radius ("Total" in Table 2). When the participants were grouped into the VDR genotypes of $A a$ and $a a$, the effect of their physical activity became statistically significant. As we have reported previously ${ }^{13}$, the BMD at distal radius was associated with the ApaI site polymorphism of the VDR gene in the opposite direction to that reported by Morrison et al. ${ }^{4}$. The effect of physical activity was significant in the unfavorable VDR genotype of $a a$, but not in the favorable genotype of $A a$ (Table 2). This implies that physical activity affects BMD only in the population with an unfavorable VDR genotype. Another important observation was that the genotype $A a$ gave a higher BMD than $a a$ only in the population with no habitual physical activity. These results show that physical activity and VDR genotypes affect the BMD independently but BMD reaches to a saturated level by either factor.

Table 1. Mean weight, height and LBM by physical activity and calcium score.

\begin{tabular}{lcccc}
\hline & $\mathrm{n}$ & \multicolumn{3}{c}{ Mean \pm SD } \\
\hline Habitual physical activity & & Weight $(\mathrm{kg})$ & Height $(\mathrm{cm})$ & LBM $(\mathrm{kg})$ \\
yes & 79 & $51.8 \pm 5.7$ & $157.6 \pm 4.5$ & $38.1 \pm 3.0$ \\
no & 41 & $52.9 \pm 8.0$ & $157.1 \pm 6.1$ & $37.9 \pm 3.5$ \\
\hline Calcium Score & & & & \\
high & 74 & $52.6 \pm 6.7$ & $156.9 \pm 5.0$ & $38.0 \pm 3.2$ \\
low & 46 & $51.6 \pm 6.3$ & $158.4 \pm 5.2$ & $38.2 \pm 3.2$ \\
\hline
\end{tabular}

LBM ; Lean body mass

No significant difference of mean weight, height and LBM between yes and no of habitual physical activity, and between high and low of calcium score. 
Since the haplotype frequency of $t / T$ was $0.09 / 0.91$ in the Japanese population ${ }^{13)}$, the TaqI site polymorphism gave uneven sample numbers for the $t, T t$ and $T T$ genotypes and was not statistically very strong. Nevertheless, the BMD of the genotype $T t$ was significantly higher than that of $T T$ only in the population with no habitual physical activity. Here again, the effect of physical activity was significant only in the unfavorable VDR genotype of $T T$.

The dietary calcium intake scored through the habit of eating calcium-containing foods suggested a cooperative interplay with the VDR genotype(Table 3 ). High scores for calcium intake indicate a trend towards higher BMD regardless of the genotype, and this trend was clearer in the $A a$ genotype than in the aa genotype.

\section{DISCUSSION}

In a survey of 470 healthy premenopausal women aged $44-$ 50 , Salamone et al. found that the VDR genotype modifies the association between physical activity and BMD at least at the femoral neck ${ }^{10}$. Within the population having the $b b$ genotype, which resulted in lower BMD, higher physical activity was associated with a higher femoral neck BMD. The effect of physical activity was less pronounced for the $B B$ and $B b$ genotypes. Their pattern was consistent with our results for Apal and TaqI sites, suggesting together that the VDR genotype affected the BMD (at least at the femoral neck and distal radius) in an independent mechanism from that of physical activity. A clearer demonstration of the differential effects of

Table 2. Mean bone mineral density by vitamin D receptor genotype and habitual physical activity.

\begin{tabular}{|c|c|c|c|c|c|c|c|}
\hline & \multicolumn{7}{|c|}{ Mean BMD of radius $\left(\mathrm{g} / \mathrm{cm}^{2}\right)$} \\
\hline & \multicolumn{7}{|c|}{ Habitual past physical activity } \\
\hline \multirow{4}{*}{ ApaI } & & Total & $\mathrm{n}$ & Yes & $\mathrm{n}$ & No & $n$ \\
\hline & $\mathrm{AA}$ & $0.502 \pm 0.061$ & 7 & $0.509 \pm 0.066$ & 6 & 0.513 & 1 \\
\hline & $\mathrm{Aa}$ & $0.515 \pm 0.054^{\mathrm{a}}$ & 53 & $0.515 \pm 0.053$ & 33 & $0.516 \pm 0.057^{b}$ & 20 \\
\hline & aa & $0.492 \pm 0.039$ & 60 & $0.500 \pm 0.037^{c}$ & 40 & $0.476 \pm 0.040$ & 20 \\
\hline \multirow{3}{*}{ TpaI } & TT & $0.499 \pm 0.048$ & 99 & $0.506 \pm 0.047^{\mathrm{d}}$ & 67 & $0.486 \pm 0.045^{\mathrm{e}}$ & 32 \\
\hline & $\mathrm{Tt}$ & $0.518 \pm 0.051$ & 20 & $0.502 \pm 0.047$ & 11 & $0.538 \pm 0.050$ & 9 \\
\hline & $\mathrm{tt}$ & 0.564 & 1 & 0.564 & 1 & & 0 \\
\hline Total & & $0.503 \pm 0.049$ & 120 & $0.506 \pm 0.047$ & 79 & $0.496 \pm 0.052$ & 41 \\
\hline
\end{tabular}

Statistical analysis was performed according to ANCOVA.

a Differs from the aa $(\mathrm{p}<0.05)$

$b$ Differs from the aa of the 'No' group $(p<0.05)$

c Differs from the 'No' group of the aa $(\mathrm{p}<0.05)$

$d$ Differs from the 'No' group of the TT $(p<0.05)$

e Differs from the tt of the 'No' group $(p<0.05)$

Table 3. Mean BMD by VDR genotype and calcium score.

\begin{tabular}{|c|c|c|c|c|c|c|c|}
\hline & \multicolumn{7}{|c|}{ Mean BMD of radius $\left(\mathrm{g} / \mathrm{cm}^{2}\right)$} \\
\hline & \multicolumn{7}{|c|}{ Calcium score } \\
\hline & & & $\mathrm{n}$ & High & $\mathrm{n}$ & Low & $\mathrm{n}$ \\
\hline & AA & $0.502 \pm 0.061$ & 7 & $0.517 \pm 0.051$ & 6 & 0.413 & 1 \\
\hline \multirow[t]{3}{*}{ Apal } & $\mathrm{Aa}$ & $0.515 \pm 0.054$ & 53 & $0.523 \pm 0.054 \mathrm{a}$ & 36 & $0.499 \pm 0.054$ & 17 \\
\hline & aa & $0.492 \pm 0.039$ & 60 & $0.495 \pm 0.035$ & 32 & $0.488 \pm 0.044$ & 28 \\
\hline & $\mathrm{TT}$ & $0.499 \pm 0.048$ & 99 & $0.506 \pm 0.047$ & 58 & $0.489 \pm 0.048$ & 41 \\
\hline \multirow[t]{2}{*}{ TpaI } & $\mathrm{Tt}$ & $0.518 \pm 0.051$ & 20 & $0.524 \pm 0.050$ & 15 & $0.502 \pm 0.055$ & 5 \\
\hline & $\mathrm{tt}$ & 0.564 & 1 & 0.564 & 1 & & 0 \\
\hline Total & & & & $0.510 \pm 0.048$ & 74 & $0.491 \pm 0.048$ & 46 \\
\hline
\end{tabular}

Statistical analysis was performed by ANCOVA.

a ; Differs from aa of High group ( $\mathrm{p}<0.05$ ) 
VDR genotype and physical activity in our study may be due to the ApaI and TaqI sites, but it is more likely due to a different way of evaluating the physical activity. As the index of physical activity, Salamone et al. estimated the total kilo-calorie expenditure per week as measured by the questionnaire. Since our questionnaire reflected the habit of participants over the period of 13-18 years old, it might be a better index of physical activity during the period of bone development. In a similar study on the interplay of VDR genotype and physical activity, Jarvinen et al. loaded the participants aged 35-45 years a progressive exercise three times a week for a period of 18 months, but they did not observe any modification of the association between VDR genotype and BMD through physical activity ${ }^{12}$. Apparently different results suggest that "habit" (over a long period) and "loading" (within a limited period) of physical activity need to be distinguished to evaluate its effect on BMD.

If we can assume that the effect of VDR genotype on BMD is due to the role of VDR in calcium metabolism, the enhanced osteocyte proliferation demonstrated by Chambers et al. by mechanical stimulation in rat tail vertebrae may provide an explanation for the differential effects of VDR genotype and physical activity ${ }^{15}$. They showed that mechanical loading induces bone formation through the expression of immediate early genes such as $c$-fos and insulin-like growth factor $I$ in otseocytes ${ }^{16}$. This animal model system suggests that physical activity enhances "osteogenesis" but not "calcification" in the subsequent step of bone formation. This may explain why the effect of physical activity on BMD was clear in the population with unfavorable VDR genotypes of $a a, T T$ and $b b$. In the favorable VDR genotypes, reduced osteogenesis due to low physical activity may be overcome by the enhancement of calcium metabolism. In the study by Rauch et al. ${ }^{11)}$, the impact of the VDR genotype was not clear probably because all of their study population consisted of physically active women.

\section{REFERENCES}

1. Seeman E, Hooper JL, Bach LA et al. Reduced bone mass in daughters of women with osteoporosis. $\mathbf{N}$ Engl $\mathbf{J}$ Med, 1989; 320: 554-558.

2. Pocock NA, Eisman JA, Hopper JL, Yeates MG, Sambrook PN, Eberi S. Genetic determinants of bone mass in adults. A twin study. J Clin Invest, 1987; 80: 706710.

3. Slemenda CW, Christian JC, Williams CJ, Norton JA, Johnston CC Jr. Genetic determinants of bone mass in adult women: a reevaluation of the twin model and the potential importance of gene interaction on heritability estimates. J Bone Miner Res, 1991; 6: 561-567.
4. Morrison NA, Qi JC, Tokita A et al. Prediction of bone density from vitamin $D$ receptor alleles. Nature, 1994; 367: 284-287.

5. Peacock M. Vitamin D receptor gene alleles and osteoporosis: a contrasting view. J Bone Miner Res, 1995; 10: 1294-1297.

6. Cooper GS, Umbach DM. Are vitamin D receptor polymorphisms associated with bone mineral density? A metaanalysis. J Bone Miner Res, 1996; 11: 1841-1849.

7. Eisman JA, Sambrook PN, Kelly PJ, Pocock NA. Exercise and its interaction with genetic influences in the determination of bone mineral density. Am J Med, 1991; 91 (Suppl 5B): 5S- 9S.

8. Dawson-Hughes B, Harris SS, Finneran S. Calcium absorption on high and low calcium intakes in relation to vitamin D receptor genotype. J Clin Endocrinol Metab, 1995; 80: 3657-3661.

9. Krall EA, Parry P, Lichter JB, Dawson-Hughes B. Vitamin $D$ receptor alleles and rates of bone loss: influences of years since menopause and calcium intake. J Bone Miner Res, 1995; 10: 978-984.

10. Salamone LM, Glynn NW, Black DM et al. Determinants of premenopausal bone mineral density: the interplay of genetic and lifestyle factors. J Bone Miner Res, 1996; 11 : 1557-1565.

11. Rauch F, Radermacher A, Danz A et al. Vitamin D receptor genotypes and changes of bone density in physically active German women with high calcium intake. Exp Clin Endocrinol Diabetes, 1997; 105: 103-108.

12. Jarvinen TLN, Jarvinen TAH, Sievanen $H$ et al. Vitamin $\mathrm{D}$ receptor alleles and bone's response to physical activity. Calcif Tissue Int, 1998; 62: 413-417.

13. Kitagawa I, Kitagawa Y, Kawase Y, Nagaya T, Tokudome S. Advanced onset of menarche and higher bone mineral density depending on vitamin $D$ receptor gene polymorphism. Eur J Endocrinol, 1998; 139: 528531.

14. Health Promotion and Nutrition Division, Health Service Bureau, Ministry of Health and Welfare. Status of National Nutrition. Results of the National Nutrition Survey in 1996. Daiichi Shuppan, Tokyo, 1998 (in Japanese).

15. Chambers TJ, Evans M, Gardner TN, Turner-Smith A, Chow JW. Induction of bone formation in rat tail vertebrae by mechanical loading. Bone Miner, 1993; 20: 167178.

16. Lean JM, Mackay AG, Chow JW, Chambers TJ. Osteocytic expression of mRNA for c-fos and IGF-I: an immediate early gene response to an osteogenic stimulus. Am J Physiol, 1996; 270 (6 Pt 1): E937-E945. 